\title{
Frostbite: Review and Current Concepts
}

\author{
Brian V. Reamy, MD, Maj, USAF
}

Background: A literature review was conducted to analyze developments in the epidemiology, pathogenesis, treatment, and prevention of frostbite injury. Increased participation in outdoor activities, as well as the epidemic of homelessness, makes knowledge of the treatment of frostbite crucial for physicians in both rural and urban areas.

Methods: A literature search, using the key words "frostbite" and "cold," was done using MEDLINE and Index Medicus. This search focused on the epidemiology, pathogenesis, treatment, and prevention of frostbite.

Results: Research done during the past 15 years has clarified the pathogenesis of frostbite injury and led to a better understanding of how to limit tissue loss. The etiology of frostbite is commonly related to alcohol use, psychiatric illness, or motor vehicle problems. The pathogenesis is linked to tissue freezing, hypoxia, and the release of inflammatory mediators. The initial clinical manifestations of frostbite injury are similar for superficial and deep tissue damage, so early treatment is identical for all injuries. Optimum therapy is based on the rapid reversal of tissue freezing by rewarming in $104-108^{\circ} \mathrm{F}$ water and the institution of oral and topical antiprostaglandin therapy to limit the release of inflammatory mediators.

Conclusion: Rapid triage and treatment of frostbite can lead to dramatic improvements in outcome and prognosis. Increased awareness of antiprostaglandin therapy and preventive measures is crucial for physicians in diverse practice environments. (J Am Board Fam Pract 1998;11:34-40.)

Research during the past 15 years has clarified the pathogenesis of frostbite injury and led to a clearer understanding of what ideal therapy comprises. New treatments now can limit the extent of tissue loss and increase the speed of rehabilitation. At the same time, the usefulness of many pharmacologic agents, the debridement of blisters, and the use of prophylactic antibiotics has been refined.

In the past frostbite was primarily a concern of the military. It has been a leading cause of devastating casualties in wars from the time of Hannibal, who lost one half of his army crossing the Alps in $218 \mathrm{BC}$, to World War II and the Korean War, where more than 10 percent of total American casualties were due to cold injuries. The German Army alone performed more than 15,000 amputations for cold-related injuries on the Russian front in the winter of 1942.1

Recently concern about frostbite injury has become more widespread. The growing epidemic

Submitted 29 April 1997.

From the Department of Family Practice, David Grant Medical Center, Travis Air Force Base, Calif. Address reprint requests to Maj Brian V. Reamy, MD, Department of Family Practice, David Grant Medical Center, 101 Bodin Circle, Travis Air Force Base, CA 94535. of homelessness in the United States has made frostbite injury and its effective treatment an issue not only for the rural physician practicing in the heart of Alaska, but also for many urban hospitals across the country. ${ }^{2,3}$ In addition, increased participation in outdoor activities and sports in inclement environments has contributed to an increased population at risk for frostbite injury and its oftentimes crippling sequelae. ${ }^{4}$

Knowledge of new research findings permits physicians to use rapid triage and proper therapy for frostbite injury, which are key in improving the prognosis and future functional level of their coldinjured patients. This literature review summarizes current insights into the epidemiology, pathogenesis, and prevention of frostbite. In addition, a suggested approach to the treatment of the frostbite-injured patient is outlined.

\section{Methods}

A search was done of the literature from 1966 to 1996 in MEDLINE and from 1960 to 1965 in Index Medicus, using the key words "frostbite," and "cold." These principal key words were crossreferenced with epidemiology, pathogenesis, signs and symptoms, diagnosis, treatment, and prevention. 


\section{Epidemiology}

There are several risk factors for frostbite injury that have been described in many large epidemiologic studies done around the world..$^{5-7}$ A 12-year study tracking injuries to 650,000 people living in Saskatchewan found the following predisposing factors: alcohol consumption (46 percent), motor vehicle problems (19 percent), and psychiatric illness (17 percent). ${ }^{8}$ Alcohol consumption is particularly devastating because it has deleterious effects on judgment and promotes peripheral vasodilatation, so it can result in subsequently more severe local injury. Other studies from Norway, Finland, and the United States have linked frostbite to homelessness, improper clothing, a history of previous cold injury, fatigue, wound infection, atherosclerosis, diabetes, and smoking. ${ }^{\text {- }}$ 12 The vasoconstrictive effects of smoking can both trigger and compound cold injury to the skin. In contrast, acclimatization, physical training, general good health, normovolemia, exercise, and adequate protective clothing can help prevent frostbite even under extremely difficult circumstances. ${ }^{13}$

Earlier studies have classified the elderly and young children as groups at high risk for frostbite injury. ${ }^{14}$ Although this grouping seems intuitively correct, the published epidemiologic studies do not show a high incidence of frostbite in these age groups. Instead, frostbite injury is most common in adults aged 30 to 49 years. ${ }^{2,3,6,8,11}$ Studies also reveal clear evidence of the anatomic sites most at risk for frostbite. The feet, the most commonly affected site, and the hand account for 90 percent of injuries reported. The next most frequently injured sites are the ears, nose, cheeks, and the penis. $2,3,5-8,11$

The need to amputate injured parts in most studies was closely correlated with the duration of cold exposure rather than temperature..$^{5,8,11} \mathrm{Al}$ though the skin freezes more quickly at colder temperatures, the amount of permanent damage is linked to the total time the tissue is frozen. The detrimental effects of ice crystal formation, intracellular dehydration, vasoconstriction, and the formation of inflammatory mediators that lead to cell death are time-dependent phenomena. For these reasons psychiatric disturbance and alcohol abuse are important risk factors for frostbite injury, because they can impair judgment and result in extended exposure to cold.

\section{Pathogenesis}

The pathophysiologic mechanism that underlies frostbite injury has been studied in humans, rabbit ears, hamster cheeks, and other models for years. Currently there is a general consensus among investigators as to the events that cause injury and ultimately cell death if frostbite is not reversed early. 4,9,13,15-17 Three pathways trigger the pathologic changes of frostbite: tissue freezing, hypoxia, and the release of inflammatory mediators. These pathways occur almost simultaneously and intensify the damage caused by each other (Figure 1).4,9,13,15-17

The freezing of tissue leads to the formation of ice crystals, first extracellularly and then intracellularly, which damage cell membranes. Subsequently, water is osmotically drawn out of cells, leading to intracellular dehydration and cell death. Additionally, freezing irreversibly denatures membrane lipid-protein complexes, triggering further cellular damage. ${ }^{9}$

The second pathway leading to damage is coldinduced local vasoconstriction, which leads to tissue hypoxia. Initially the body responds to tissue cooling by alternating cycles of vasoconstriction and vasodilatation, "the hunting reaction." 15 When the maintenance of overall body core temperature is threatened by continued exposure to cold, the hunting reaction ceases and local vasoconstriction persists, triggering hypoxia, acidosis, and increased local blood viscosity. Eventually capillary blood flow ceases, arterioles and venules become thrombosed, and irreversible tissue hypoxia occurs.

Endothelial injury, hypoxia, and local thrombosis promote the third pathway of damage-the release of inflammatory mediators. The release of the potent prostaglandins $\mathrm{PGF}_{2}$ and thromboxane $\mathrm{A}_{2}$ trigger further vasoconstriction, platelet aggregation, and blood vessel thrombosis, which worsen endothelial damage and set off a further cascade of hypoxia and cell death.9,13,15-17 These mediators have been found in cold-injured tissues and the blister fluid of damaged skin. Furthermore, they have been shown to be the prime mediators of progressive tissue ischemia in both coldand heat-injured skin. ${ }^{16,17}$ The release of these mediators peaks during rewarming, and cycles of recurrent freezing and warming increase their tissue levels. ${ }^{16}$ Consequently, rewarming should not be attempted until the thawed body part can be 


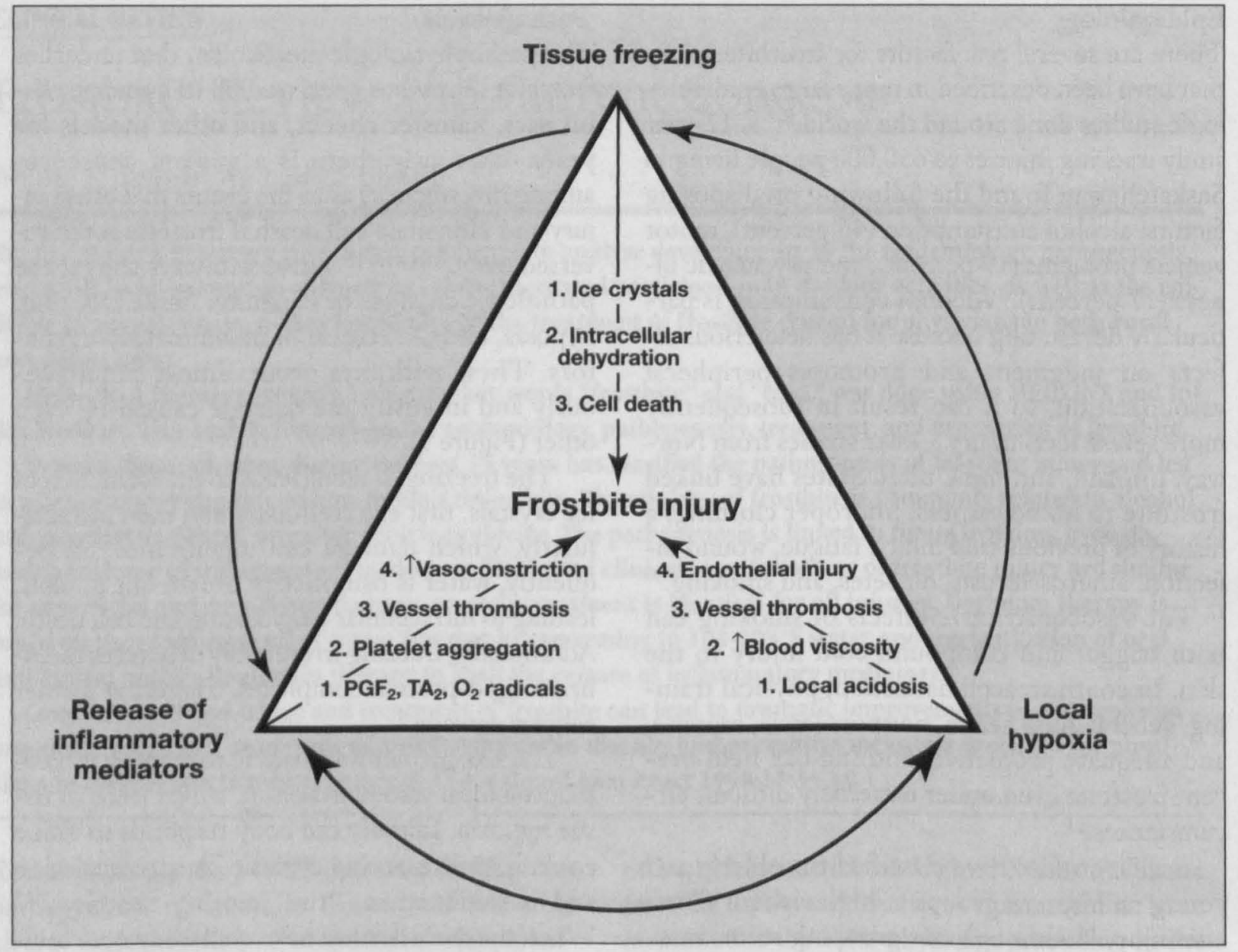

Figure 1. Pathogenesis of frostbite injury. $\mathrm{PGF}_{2}$ - prostaglandin $\mathrm{F}_{2}, \mathrm{TA}_{2}$ - thromboxane $\mathrm{A}_{2}, \mathrm{O}_{2}$ - molecular oxygen.

kept thawed and refreezing can be prevented.

Rapid rewarming to stop freezing, increasing blood flow to limit local hypoxia, and administering medications to block the release of inflammatory mediators would clearly reverse the three pathways of tissue damage. These tools are the foundation of effective treatment of frostbite.

\section{Clinical Manifestations}

Classically, frostbite has been categorized according to four degrees of injury. This description is applied after rewarming, because most injuries appear to be similar at the time of initial evaluation. With first-degree injury there is numbness, a central white plaque, and surrounding erythema. Second-degree injury causes blisters filled with a clear or milky fluid that develop during the first 24 hours. These blisters are surrounded by erythema and edema. Third-degree injury triggers hemorrhagic blisters, which are a sign of deeper tissue injury, that result in a hard black eschar 2 weeks later. Fourth-degree injury is char- acterized by complete necrosis and loss of tissue.

These classifications, which are useful for describing what is seen clinically, have not been found to help predict the extent of future tissue damage. Other investigators prefer to describe only two classes of injury, superficial (first- and second-degree) and deep (third- and fourth-degree), since the treatment for all classes of frostbite is the same until tissue demarcation between viable and nonviable tissue occurs at 22 to 45 days after injury. ${ }^{18}$

The symptoms of frostbite injury are fairly uniform and can help predict the severity of injury. At first most patients describe a cold numbness that progresses to a feeling of clumsiness in the involved part. After rewarming, this numbness will give way to a severe throbbing pain that can persist for days to weeks. This throbbing sensation then results in a mild tingling sensation in the involved part; an electric shock is also described by some patients. Sensory loss, increased cold sensitivity, and hyperhidrosis can also develop and per- 
1. Evaluate for hypothermia, concomitant injury, or complicating problems

2. Rapidly rewarm the affected areas in precisely controlled water at $104-108^{\circ} \mathrm{F}\left(40-42^{\circ} \mathrm{C}\right)$ until thawing is complete (15 to $30 \mathrm{~min}$, or skin returns to a red-purple color and regains a pliable texture)

3. Debride clear or white blisters and apply aloe vera (at least $70 \%$ concentration without alcohol or perfume). Cover with loose, bulky, protective dressing. Repeat aloe vera application every $6 \mathrm{~h}$. Hemorrhagic blisters should be left intact but with aloe vera applied

4. Splint and elevate the extremity

5. Administer ibuprofen orally at $12 \mathrm{mg} / \mathrm{kg} / \mathrm{d}$ in divided doses 2 to 4 times a day

6. Administer tetanus toxoid and tetanus immune globulin if $>10 \mathrm{y}$ since last tetanus booster

7. Administer intravenous penicillin, 500,000 U every $6 \mathrm{~h}$ for $72 \mathrm{~h}$; add further antibiotics only if evidence of infection

8. Control pain with parenteral narcotics (morphine or meperidine) as needed

9. Administer daily hydrotherapy in $40^{\circ} \mathrm{C}$ water with hexachlorophene for 30 to $60 \mathrm{~min}$

10. Prohibit smoking

sist for years after the initial injury. ${ }^{1}$ Arthritis, growth plate damage, and chronic pain are less common long-term sequelae. ${ }^{15}$

Favorable findings at the time of initial physical examination include sensation to pinprick, skin that will indent when pressure is applied (indicating elasticity of viable deeper skin), normal color, and large blisters filled with clear fluid. Small vesicles filled with dark, blood-tinged fluid, nonblanching cyanosis, and skin that feels wooden to the touch and does not indent with pressure herald a poor prognosis. ${ }^{19}$

\section{Diagnosis}

In addition to physical examination findings, there are several diagnostic tests that have been used to help predict the severity and prognosis of the frostbite injury. Techniques have included conventional radiography, angiography, digital plethysmography, Doppler flow studies, laserDoppler flow studies, thermography, NMR $31 \mathrm{P}$ spectroscopy, bone scintigraphy (technetium 99), and other forms of intravenous radioisotope scintigraphy to assess blood flow. ${ }^{4,13}$ No tests are definitive in the first 3 to 5 days immediately after rewarming because of the effects of persistent vascular spasm and instability. 4,9,20

During the initial period after thawing, some tests can be used to assess the boundaries of tissue viability and thus help plan surgical removal of devitalized tissue. From 1 to 3 weeks after injury, Doppler studies and angiography can help assess vascular status, ${ }^{4}$ and by 2 to 3 weeks after injury, bone scintigraphy can help demarcate areas of severe frostbite that will need amputation. ${ }^{20,21} \mathrm{Nev}-$ ertheless, the difficulty of using initial physical examination findings to predict prognosis and the lack of any diagnostic tests that definitively guide therapy in the first days after injury require that a comprehensive treatment regimen be applied for all cases of frostbite injury.

\section{Treatment}

The treatment of frostbite is directed at reversing the pathologic effects of ice crystal formation, vasoconstriction, and the release of inflammatory mediators. It can be divided into three phases: prethaw field care phase, immediate hospital care phase, and postthaw care phase, which continues for several weeks. The field care phase begins once frostbite is suspected. Transport to emergency services should not be delayed. Field warming should be undertaken only if refreezing can be prevented and the estimated time until arrival at a hospital is expected to exceed 2 hours. ${ }^{9}$ The injured part should be protected with a splint and bulky loose padding. The patient should have wet clothing removed to prevent hypothermia. Rubbing the fragile frostbitten extremity with snow, cloth, or the rescuer's hand is harmful. Alcohol and smoking are prohibited during transport. All prehospital treatments should focus on preventing partial thawing and refreezing, which causes much more devastating damage from the increased release of inflammatory mediators than does a simple prolonged freezing. ${ }^{4,16}$

The immediate care phase begins upon arrival at the hospital. The current state of the art in frostbite care is based in large part on the work of Heggers and McCauley (Table 1). 13,16,17,22 The injured part should be rapidly warmed in water maintained within a precise temperature range of $104^{\circ} \mathrm{F}$ to $108^{\circ} \mathrm{F}\left(40^{\circ} \mathrm{C}\right.$ to $\left.42^{\circ} \mathrm{C}\right)$ for 15 to 30 minutes to stop quickly any further ice crystal formation and to re- 
Table 2. Possible Adjuvant Therapies for Frostbite.

\begin{tabular}{ll}
\hline Agent or Procedure & Usefulness \\
\hline Low molecular weight dextran & Doubtful \\
Heparin & None \\
Coumadin & None \\
Steroids & None \\
Vitamin C & Doubtful \\
Streptokinase or urokinase & Doubtful \\
Surgical sympathectomy & None early, possibly \\
& useful late \\
Hyperbaric oxygen & Possible \\
Intra-arterial reserpine & Possible (as a late \\
& intervention) \\
Tissue plasminogen activator & Possible \\
Prostaglandin $E_{1}$ analogs & Possible \\
Nifedipine & Possible \\
Pentoxifylline & Possible \\
Superoxide dismutase & Possible \\
\hline
\end{tabular}

verse vasoconstriction. ${ }^{15}$ Water outside this range can exacerbate tissue damage, and dry heat can trigger uneven warming and cause burn injury to the numb, damaged tissue. ${ }^{16,23}$ A red-purple appearance and pliable texture of the involved part signal the end of vasoconstriction and are signs to cease warming. ${ }^{15,23}$ Blisters containing clear or milky fluid, which is rich in inflammatory mediators, should be debrided and covered with aloe vera, a potent antiprostaglandin agent, every 6 hours. ${ }^{15-17,24}$ Splinting, elevating, and wrapping the affected part in a loose, protective dressing should follow the application of aloe vera cream. Hemorrhagic blisters should be left intact.

An immediate oral administration of ibuprofen at a dose of $12 \mathrm{mg} / \mathrm{kg} / \mathrm{d}$ provides systemic antiprostaglandin activity that limits the cascade of inflammatory damage. ${ }^{16,17}$ Ibuprofen is also a more potent inhibitor of thromboxane than are other anti-inflammatory drugs. ${ }^{16,17}$ Aspirin is not recommended because it prolongs blockade of all prostaglandin synthesis, including some prostaglandins that are beneficial for tissue healing. ${ }^{17}$

Tetanus toxoid is given; tetanus immune globulin is reserved for patients for whom more than 10 years have passed since their last booster. ${ }^{25}$ Penicillin, 500,000 U every 6 hours, is administered during the first 72 hours when the skin is edematous, because the edema makes the skin more susceptible to infection by gram-positive organisms. ${ }^{15,26}$ Further antibiotic use is indicated only if there is evidence of infection. ${ }^{16,17} \mathrm{Par}$ - enteral narcotic analgesia is usually required during rewarming because the patient will experience intense pain as sensation returns to the cold-injured part.

After this initial treatment further modalities can optimize healing and minimize tissue loss during the post-thaw phase of care. Almost all patients, except those with the most minimal damage, should be admitted to the hospital. Given that alcohol overindulgence, psychiatric disease, and homelessness are common features of the frostbitten patient, immediate discharge is rarely prudent. Subsequent wound care, which can be intense, is also most easily accomplished in the hospital.

Daily hydrotherapy in water with hexachlorophene at $40^{\circ} \mathrm{C}$ aids debridement of devitalized tissue. ${ }^{15-17}$ Physical therapy to enhance flexibility and strength is begun as soon as the edema resolves. ${ }^{15}$ Escharotomy or fasciotomy is performed if circulation is impaired or a compartment syndrome develops in the involved extremity. ${ }^{15-17}$ Limited tissue debridement is undertaken only when infection cannot be controlled. ${ }^{27} \mathrm{De}-$ finitive amputation of tissue should be delayed until 22 to 45 days after injury, when the demarcation between viable and nonviable tissue is clear. ${ }^{18}$ Amputation done before this interval will be based on an incorrect estimate of the need for tissue removal, because the early clinical signs are similar for most degrees of injury.

Numerous adjuvant therapies for frostbite have undergone trials with varying degrees of success. $A$ list and summary of the current usefulness of these therapeutic alternatives is shown in Table 2.4,13,15,28-41 Many have been tested only in animal models, and further randomized trials in humans are needed before their helpfulness can be definitively established. At present, agents that inhibit formation of free radicals, such as superoxide dismutase, and agents that have platelet antiaggregant activity, such as pentoxifylline, hold some promise as adjunctive agents with negligible associated risks. ${ }^{29,36}$

\section{Prevention}

The world's highest mountain peaks have been climbed without cold injury, and the military engages in maneuvers in cold environments with a minimum of cold injuries. ${ }^{1}$ Protective clothing and footwear have improved dramatically with the introduction of synthetic fabrics that are lighter, 
more insulating, and faster-drying than wool. The military in particular has come up with many preventative measures to limit cold injuries. ${ }^{1}$

The foundation of these measures comprises adequate knowledge of the behaviors that lead to cold injury, experienced leadership, good physical condition, adequate nutritional status, normal hydration, elimination of smoking and alcohol use, and investment in appropriate clothing. 1,5,23,42 All clothing should be fitted to prevent constriction of the extremities. Clothing should be worn in layers with air spaces between the layers and covered by an outer wind- and water-resistant garment. Layering conserves body heat, is flexible, and permits the removal of layers during strenuous exertion. It also prevents the clothing from becoming perspiration soaked or otherwise wet, which can dramatically increase the risks of cold injury.

Footwear should also be layered within an outer waterproof barrier. Military vapor barrier boots and Native Alaskan-inspired mukluk boots are models of these principles. Hand coverings should also be layered, with a protective water-repellent outer mitten over fingered and layered inner gloves. The mitten can be removed to permit work requiring dexterity. Habituation to cold weather can also limit the risk of cold injury. ${ }^{42}$ The reasons for this protective effect remain controversial, however, because it is difficult to sort out the behavioral benefits of increased knowledge gained from living in a cold environment from any possible physiologic effects that occur after time in a cold climate. ${ }^{13,23,42}$

Finally, it is critical to reduce the population at risk for frostbite. Education in frostbite prevention for participants in outdoor sports can be incorporated into the preparticipation physicals. Further education at the time of frostbite treatment would also help to reduce subsequent reinjury. Nevertheless, a substantial reduction in risk will occur only when there is a decrease in two of our nation's most vexing social problems, alcoholism and homelessness.

\section{Conclusion}

The rise in homelessness and increase in outdoor cold weather activities have made frostbite a common occurrence in urban as well as remote rural areas. Within the past 15 years medical research has been able to clarify the best approach to the diagnosis, treatment, and prevention of frostbite injury. A new understanding of the importance of inflammatory mediators in worsening frostbite injury has led to powerful new treatments, and applying these treatment precepts, with special attention to rapid rewarming at $104^{\circ} \mathrm{F}$ to $108^{\circ} \mathrm{F}$, debriding blisters filled with milky fluid, and administering the antiprostaglandin agents ibuprofen and aloe vera, will optimize the outcome for the cold-injured patient. Future research should be directed toward outlining the benefits of other adjuvant therapies, such as free radical inhibitors and platelet antiaggregants.

\section{References}

1. Bowen TE, Bellamy RF. Cold injury. In: Emergency War Surgery. Washington, DC: Department of Defense, US Government Printing Office, 1988.

2. Pulla RJ, Pickard LJ, Carnett TS. Frostbite: an overview with case presentations. J Foot Ankle Surg 1994;33:53-63.

3. Antri-Poika I, Pohjolainen T, Alaranta H. Severe frostbite of the upper extremities-a psychosocial problem mostly associated with alcohol abuse. Scand J Soc Med 1990;18:59-61.

4. Foray J. Mountain frostbite. Current trends in prognosis and treatment (from results concerning 1261 cases). Int J Sports Med 1992;13(Suppl 1):S193-6.

5. Rosen L, Eltvik L, Arvesen A, Stranden E. Local cold injuries sustained during military service in the Norwegian Army. Arctic Med Res 1991;50:159-65.

6. Hermann G, Schecter DC, Owens JC, et al. The problem of frostbite in civilian medical practice. Surg Clin North Am 1963;43:519-36.

7. Ervasti E. Frostbites of the extremities and their sequelae. Acta Chir Scand Suppl 1962;299:1-69.

8. Valnicek SM, Chasmar LR, Clapson JB. Frostbite in the prairies: a 12-year review. Plast Reconstr Surg 1993;92:633-41.

9. Bracker MD. Environmental and thermal injury. Clin Sports Med 1992;11:419-36.

10. Christenson C, Stewart C. Frostbite. Am Fam Physician 1984;30:111-22.

11. Boswick JA Jr, Thompson JD, Jonas RA. The epidemiology of cold injuries. Surg Gynecol Obstet 1979;149:326-32.

12. Kyosola K. Clinical experiences in the management of cold injuries: a study of 110 cases. J Trauma 1974; 14:32-6.

13. McCauley RL, Smith DJ, Robson MC, Heggars JP. Frostbite and other cold-induced injuries. In: Auerbach PS, editor. Wilderness medicine. 3rd ed. St Louis: Mosby, 1995.

14. Washburn B. Frostbite. N Engl J Med 1962;266:97489.

15. Britt LD, Dascombe WH, Rodriguez A. New horizons in management of hypothermia and frostbite injury. Surg Clin North Am 1991;71:345-70. 
16. Heggers JP, Robson MC, Manavalen K, Weingarten MD, Carethers JM, Boertman JA, et al. Experimental and clinical observations on frostbite. Ann Emerg Med 1987;16:1056-62.

17. McCauley RL, Hing DN, Robson MC, Heggers JP. Frostbite injuries: a rational approach based on the pathophysiology. J Trauma 1983;23:143-7.

18. Orr KD, Fainer DC. Cold injuries in Korea during winter of 1950-1951. Fort Knox, Ky: Army Medical Research Laboratory, 1951.

19. Mills WJ Jr. Summary of treatment of the cold-injured patient. Alaska Med 1973;15(2):56-62.

20. Miller BJ, Chasmar LR. Frostbite in Saskatoon: a review of 10 winters. Can J Surg 1980;23:423-6.

21. Mehta RC, Wilson MA. Frostbite injury: prediction of tissue viability with triple-phase bone scanning. $\mathrm{Ra}$ diology 1989;170:511-4.

22. McCauley RL, Heggers JP, Robson MC. Frostbite. Methods to minimize tissue loss. Postgrad Med 1990;88(8):67-8, 73-7.

23. Fritz RL, Perrin DH. Cold exposure injuries: prevention and treatment. Clin Sports Med 1989; 8:111-28.

24. Page RE, Robertson GA. Management of the frostbitten hand. Hand 1983;15:185-91.

25. Didlake RH, Kukora JS. Tetanus following frostbite injury. Contemp Orthop 1985;10:69-74.

26. Cold hypersensitivity. Br Med J 1975;1:643-4.

27. Holm PC, Vanggaard L. Frostbite. Plast Reconstr Surg 1974;54:544-51.

28. Schiavone FM, Osborn HH. Frostbite. Hosp Physician 1988jan: 16-31.

29. Mills WJ Jr. Comments on this issue of Alaska medicine-from then (1960) until now (1993). Alaska Med 1993;35:70-87.

30. Schumaker HB. Studies in experimental frostbite: the effect of heparin in preventing gangrene. Surgery 1947;22:900-5.
31. Okuboye JA, Ferguson CC. The use of hyperbaric oxygen in the treatment of experimental frostbite. Can J Surg 1968;11:78-84.

32. Snider RL, Porter JM. The treatment of experimental frostbite with intra-arterial sympathetic blocking drugs. Surgery 1975;77:557-61.

33. Purkayastha SS, Chhabra PC, Verma SS, Selvamurthy W. Experimental studies on the treatment of frostbite in rats. Indian J Med Res 1993;98:178-84.

34. Salimi Z, Wolverson MK, Herbold DR, Vas W, Salimi A. Treatment of frostbite with i.v. streptokinase. AJR Am J Roentgenol 1987;149:773-6.

35. Skolnick AA. Early data suggest clot-dissolving drug may help save frostbitten limbs from amputation. JAMA 1992;267:2008-10.

36. Miller MB, Koltai PJ. Treatment of experimental frostbite with pentoxifylline and aloe vera cream. Arch Otolaryngol Head Neck Surg 1995;121:678-80.

37. Saito $S$, Shimada $H$. Effect of prostaglandin $E_{1}$ analogue administration on peripheral skin temperature at high altitude. Angiology 1994;45:455-60.

38. Groechenig E. Treatment of frostbite with iloprost. Lancet 1994;344:1152-3.

39. Rustin MH, Newton JA, Smith NP, Dowd PM. The treatment of chilblains with nifedipine: the results of a pilot study, a double-blind placebo-controlled randomized study and a long-term open trial. $\mathrm{Br} \mathrm{J}$ Dermatol 1989;120:267-75.

40. Golding MR. Protection from early and late sequelae of frostbite by regional sympathectomy. Surgery 1963; 53:303-306.

41. Bouwman DL, Morrison S, Lucas CE, Ledgerwood AM. Early sympathetic blockade for frostbite-is it of value? J Trauma 1980;20:744-9.

42. Kappes B, Mills W, O'Malley J. Psychological and psychophysiological factors in prevention and treatment of cold injuries. Alaska Med 1993;35:131-40. 